\title{
Inherited isolated adrenal insufficiency due to partial CYP11A1 deficiency
}

INSERM

\section{Source}

INSERM. (1999). Orphanet: an online rare disease and orphan drug data base. Inherited isolated adrenal insufficiency due to partial CYP11A1 deficiency. ORPHA:289548

Inherited isolated adrenal insufficiency due to partial CYP11A1 deficiency is a rare, genetic, chronic, primary adrenal insufficiency disorder, due to partial loss-of-function CYP11A1 mutations, characterized by early-onset adrenal insufficiency without associated abnormal external male genitalia. Patients present with signs of adrenal crisis, including electrolite abnormalities, severe weakness, recurrent vomiting and seizures. Ultrasound reveals absent (or very small) adrenal glands. 